\title{
Linear Optical Properties of Zinc Borotellurite Glass Doped with Lanthanum Oxide Nanoparticles for Optoelectronic and Photonic Application
}

\author{
Faznny Mohd Fudzi, Halimah Mohamed Kamari, \\ Amirah Abd Latif, and Azlan Muhammad Noorazlan \\ Glass and Dielectric Laboratory, Physics Department, Faculty of Science, Universiti Putra Malaysia (UPM), \\ 43400 Serdang, Selangor, Malaysia
}

Correspondence should be addressed to Halimah Mohamed Kamari; hmk6360@gmail.com

Received 11 October 2016; Revised 3 March 2017; Accepted 5 March 2017; Published 29 March 2017

Academic Editor: Paulo Cesar Morais

Copyright (C) 2017 Faznny Mohd Fudzi et al. This is an open access article distributed under the Creative Commons Attribution License, which permits unrestricted use, distribution, and reproduction in any medium, provided the original work is properly cited.

\begin{abstract}
Enhancing the optical properties of glasses for the sake of optical application in various fields is an ongoing challenge in materials science and technology. Thus, the optical properties of zinc borotellurite glass doped with lanthanum oxide nanoparticles $\left(\mathrm{La}_{2} \mathrm{O}_{3}\right.$ $\mathrm{NPs})$ with the chemical composition of $\left\{\left[\left(\mathrm{TeO}_{2}\right)_{0.7}\left(\mathrm{~B}_{2} \mathrm{O}_{3}\right)_{0.3}\right]_{0.7}(\mathrm{ZnO})_{0.3}\right\}_{1-x}\left(\mathrm{La}_{2} \mathrm{O}_{3} \mathrm{NPs}\right)_{x}$, where $x=0.01,0.02,0.03,0.04$, and 0.05 molar fraction, have been investigated. Characterization techniques such as X-ray diffraction, Fourier Transform Infrared Spectroscopy, and Ultraviolet-Visible Spectroscopy are employed to yield the structural properties and optical parameter of the glass. The amorphous nature of the fabricated glasses is confirmed with the presence of a broad hump via XRD diffraction pattern. The decreasing amount of high polarizable nonbridging oxygen as the concentration of $\mathrm{La}_{2} \mathrm{O}_{3} \mathrm{NPs}$ increases has contributed to the increasing trend of energy band gap in the range of 2.70 to $3.52 \mathrm{eV}$ and decreasing value of refractive index between 2.34 and 2.48 . The fabricated glasses that have a higher refractive index than the widely used fiber material, pure silica glass, indicate that zinc borotellurite glass doped with lanthanum nanoparticles is a promising material to be applied as optical fibers.
\end{abstract}

\section{Introduction}

Glasses doped with rare earth element are materials with high potential to be applied in many fields including optical fibers, amplifiers, laser wave guides, and magneto-optical devices [1]. The properties of oxide glasses strongly rely on the composition and local structure of the glass structure [2]. Lately, in pursuance of synthesizing fiber optics with better linear and nonlinear optical properties, tellurite based glass doped with rare earth element has been extensively studied. Tellurite glasses become the best candidate to be used to synthesize photonics devices because of its low melting temperature, good thermal stability, low phonon energy, and high linear and nonlinear refractive index [3-5].

Meanwhile, boron oxide is an excellent glass former that owns the ability to exist in both three and four coordinated environments, has high strength of covalent $\mathrm{B}-\mathrm{O}$ bond, is able to form stable glasses, and has high potential to be designed as new optical devices because of their good rare earth ions solubility [6,7]. Zinc oxide is added in the glass matrix to increase glass forming ability and to ensure low rates of crystallization in the glass system [8].

Lanthanum oxide on the other hand has a band gap value of $4.3 \mathrm{eV}$ and a hexagonal crystal structure and is used in various fields such as in optoelectronic devices and as dopant in camera glass lens to enhance sharpness and to improve clarity of the image. Other than that, lanthanum oxide is used to produce a ceramic superconductor in which the magnetic properties of the lanthanum containing ceramic superconductor could be modified by only inducing light [9].

Extraordinary properties of rare earth ions due to the optical transitions in the intra- $4 \mathrm{f}$ shell have made rare earth ion a popular dopant in various glass systems [10]. According to Vajtai, when lanthanide nanocrystals is incorporated and 
well distributed in a glass system, optical properties of the material will undergo some changes due to the synergy between the lanthanide crystal and glass components [11]. The objectives for doping rare earth ions and nanosized rare earth ions are to explore and understand the local structural variations that occurred due to the addition of dopant in the host glasses.

Based on previous researches done by Halimah et al., Azlan et al., and Hajer et al., when zinc borotellurite glass is doped with rare earth ions with $4 \mathrm{f}$ electrons such as erbium, erbium nanoparticles, samarium, and samarium nanoparticles, the optical properties of the samples were proven to be improved where the optical band gap has a decreasing trend while refractive index values increase [1216]. In this research, lanthanum, that is, the only element in the lanthanide group that does not have any $4 \mathrm{f}$ electron, is studied to determine whether lanthanum also possess the same extraordinary properties as other lanthanide elements that own $4 \mathrm{f}$ electrons.

The study of the optical properties of a glass is an essential prerequisite in order to attain high quality optical systems. The application of zinc borotellurite glass doped with $\mathrm{La}_{2} \mathrm{O}_{3}$ NPs in optoelectronic and photonic field can only be ascertained by fully understanding the behavior of $\mathrm{La}_{2} \mathrm{O}_{3} \mathrm{NPs}$ ions in a glassy matrix through a planned research.

\section{Experimental Procedure}

Glasses with the chemical formula of $\left\{\left[\left(\mathrm{TeO}_{2}\right)_{0.7}\left(\mathrm{~B}_{2} \mathrm{O}_{3}\right)_{0.3}\right]_{0.7}(\mathrm{ZnO})_{0.3}\right\}_{1-x}\left(\mathrm{La}_{2} \mathrm{O}_{3} \mathrm{NPs}\right)_{x}$, where $x=0.01,0.02,0.03,0.04$, and 0.05 molar fraction, were fabricated via melt quenching method. $13 \mathrm{~g}$ batch of glass samples with appropriate amount of analytical reagent grade $\mathrm{TeO}_{2}$ (99.99\%, Alfa Aesar), $\mathrm{B}_{2} \mathrm{O}_{3}$ (98.5\%, Alfa Aesar), $\mathrm{ZnO}$ (99.99\%, Alfa Aesar), and $\mathrm{La}_{2} \mathrm{O}_{3}$ NPs (99.99\%, Nanostructured \& Amorphous Materials, Inc.) were weighed using a digital weighing machine with an accuracy of $\pm 0.0001 \mathrm{~g}$ and were placed in an alumina crucible. After stirring the chemical mixture using a glass rod for 30 minutes, the crucible was transferred to an electrical furnace for preheating process at $400^{\circ} \mathrm{C}$ for a period of 1 hour in order to remove excess water molecule in the chemical mixture [17].

Next, the crucible was moved to second furnace with the temperature $900^{\circ} \mathrm{C}$ for 2 hours to undergo melting process. A stainless steel mould was placed in the first furnace to be preheated to reduce the possibility of glass cracking due to mechanical stress as the glass was casted [18]. After 2 hours of melting process, the melt was casted into the preheated mould and immediately transferred to the first furnace to be annealed for 1 hour at $400^{\circ} \mathrm{C}$. The purpose of annealing process is to remove air bubbles and to eliminate the stress present in the glass system [19]. Finally, glass sample was left in the furnace to be cooled after the furnace is switched off.

For the physical properties of prepared glass samples, density measurement is done at room temperature by using distilled water as the immersion liquid while molar volume values are calculated from the density results.

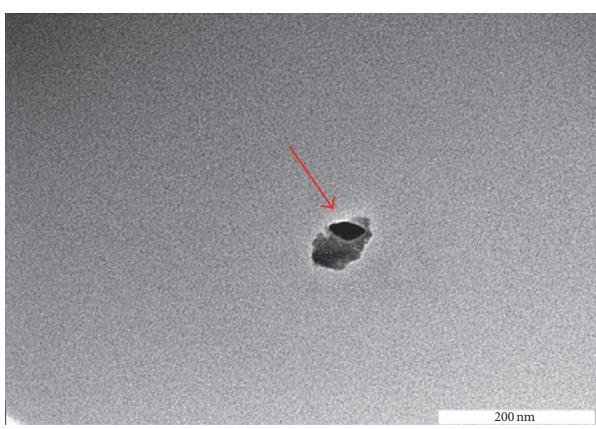

FIGURE 1: TEM image of zinc borotellurite glass doped with 0.03 molar fraction of $\mathrm{La}_{2} \mathrm{O}_{3}$ NPs.

For structural properties characterization techniques, bulk glass samples were crushed and grinded in order to obtain fine powder. For XRD testing, the fine powder was placed on the aluminum holder in the X'PERT PRO PW304 with $\mathrm{Cu} \mathrm{K} \mathrm{K}_{\alpha 1}$ radiation which was controlled by a computer system. The instrument was connected to a computer in order to generate the XRD pattern and also to record data at $2 \theta$ angles in the range of $80^{\circ} \geq \theta \geq 20^{\circ}$ for 30 minutes with the step of 0.02 degrees during the scanning process. The fine powder was characterized by employing Mattson 5000 FTIR Spectrometer in the frequency range of $200-4000 \mathrm{~cm}^{-1}$ at room temperature to obtain the FTIR spectra.

For optical properties characterization technique, the fabricated glasses were cut by utilizing Isomet Buehler low speed saw machine and both sides of the surface of the glass samples were polished by using silicon carbide paper of different grid. Bulk glass sample that has been polished on both sides with thickness $\sim 2 \mathrm{~mm}$ was placed in the sample holder of UV-1650PC UV-Vis Spectrophotometer (Shimadzu). The light source from Xenon light flash was used for characterization process where the optical absorption spectra in the range of 220 to $2600 \mathrm{~nm}$ were recorded by the computer system connected to the instrument.

In order to prove the existence of La NPs in the glass system, sample with 0.03 molar fraction of La NPs was sent for Transmission Electron Microscope (TEM) LEO 912AB. Fine powder form of fabricated glass sample was dispersed uniformly in acetone solution and transferred on the sample holder of the instrument. The scanning process to retrieve TEM images was controlled by the computer connected to the instrument.

\section{Result and Discussions}

3.1. Transmittance Electron Microscope (TEM). By using TEM, the existence of $\mathrm{La}_{2} \mathrm{O}_{3}$ NPs inside the glass matrix can be proven. TEM image of the $\mathrm{La}_{2} \mathrm{O}_{3}$ NPs in the glass matrix was revealed in Figure 1.

The average size of high purity raw $\mathrm{La}_{2} \mathrm{O}_{3}$ NPs powder ranges from 15 to $30 \mathrm{~nm}$ while the size of $\mathrm{La}_{2} \mathrm{O}_{3} \mathrm{NPs}$ after it was incorporated in the glass matrix is $30.39 \mathrm{~nm}$. Clustering and growth of nanoparticles that occur as a result of annealing 


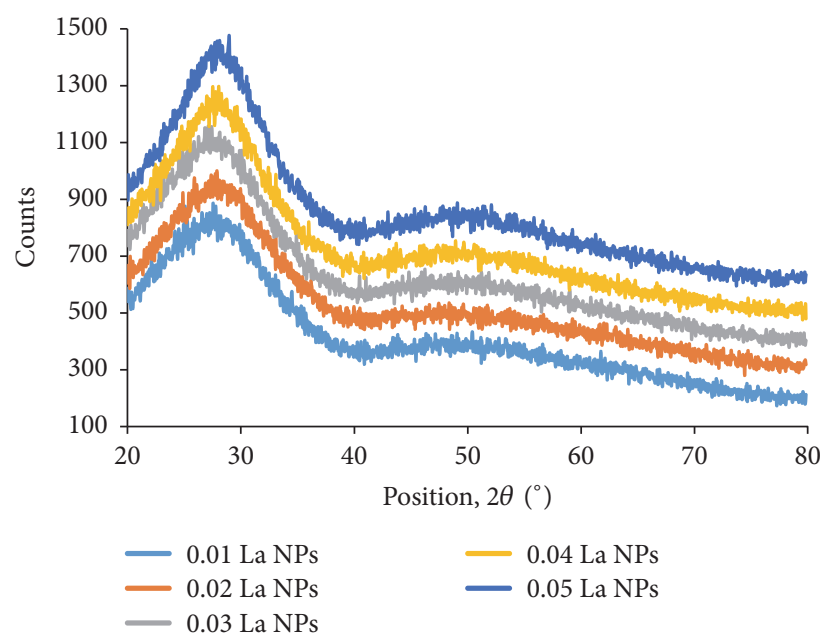

FIGURE 2: XRD diffraction pattern of $\left\{\left[\left(\mathrm{TeO}_{2}\right)_{0.7}\left(\mathrm{~B}_{2} \mathrm{O}_{3}\right)_{0.3}\right]_{0.7}(\mathrm{ZnO})_{0.3}\right\}_{1-x}\left(\mathrm{La}_{2} \mathrm{O}_{3} \quad \mathrm{NPs}\right)_{x}$ with different molar fraction of $\mathrm{La}_{2} \mathrm{O}_{3}$ NPs.

the glass sample close to or higher than transition temperature $\left(T_{g}\right)$ [20] have led to the increment of size of $\mathrm{La}_{2} \mathrm{O}_{3} \mathrm{NPs}$.

\subsection{X-Ray Diffraction (XRD). Nondestructive characteriza-} tion technique, $X$-ray diffraction (XRD), has been extensively used in order to determine the crystallinity, crystal structures, and lattice constants of nanoparticles and thin film [20]. Figure 2 depicted the $\mathrm{x}$-ray diffraction pattern for the prepared glass samples.

From Figure 2, the presence of a broad hump indicates that the fabricated samples do not have long range periodic lattice arrangement. The absence of sharp lines and peaks revealed that the samples are amorphous in nature. Since glasses do not have uniformly spaced planes of atoms, thus no sharp diffraction pattern will be observed in the diffraction pattern [21].

3.3. Fourier Transform Infrared Spectroscopy (FTIR). Numerous tools have been utilized to characterize the glassy state and to illustrate the structure of a material, for instance, the vibrational spectroscopy [22]. Electromagnetic radiation that interacts with vibrational excitation will affect the transmission or scattering of light, thus making the use of infrared spectroscopy as a vibrational probe possible [23]. FTIR spectra for the fabricated glass samples are revealed in Figure 3 while band assignment is summarized and listed in Table 1.

The FTIR transmission spectra consist of two broad absorption bands at $1230-1236 \mathrm{~cm}^{-1}$ and $638-644 \mathrm{~cm}^{-1}$ while a small shoulder that lies between 993 and $996 \mathrm{~cm}^{-1}$ only appeared in 0.04 and 0.05 molar fraction of $\mathrm{La}_{2} \mathrm{O}_{3}$ NPs.

Vibration mode of boron oxide consists of asymmetric stretching vibration of the $\mathrm{B}-\mathrm{O}$ bonds in $\mathrm{BO}_{3}$ units that develop at $1200-1600 \mathrm{~cm}^{-1}$ and $\mathrm{B}-\mathrm{O}$ bond stretching of the tetrahedral $\mathrm{BO}_{4}$ units that lie from 800 to $1200 \mathrm{~cm}^{-1}$ [24]. Meanwhile, tellurite oxide can be divided into two types of structural configuration units that are trigonal bipyramid,

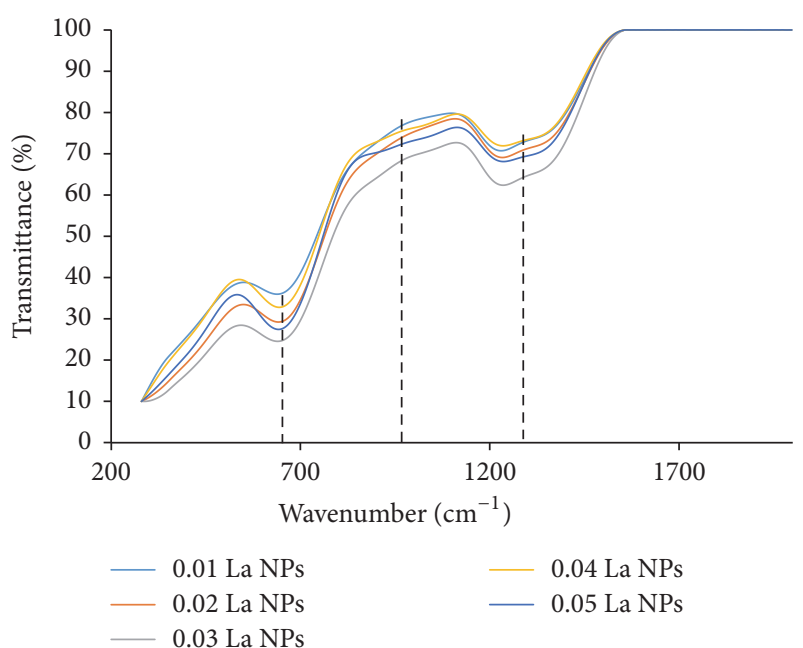

FIGURE 3: FTIR spectra of $\left\{\left[\left(\mathrm{TeO}_{2}\right)_{0.7}\left(\mathrm{~B}_{2} \mathrm{O}_{3}\right)_{0.3}\right]_{0.7}(\mathrm{ZnO})_{0.3}\right\}_{1-x}$ $\left(\mathrm{La}_{2} \mathrm{O}_{3} \mathrm{NPs}\right)_{x}$ with different molar fraction of $\mathrm{La}_{2} \mathrm{O}_{3} \mathrm{NPs}$.

$\mathrm{TeO}_{4}$, and trigonal pyramid, $\mathrm{TeO}_{3}$. The stretching vibration of $\mathrm{TeO}_{3}$ group is between 650 and $700 \mathrm{~cm}^{-1}$ while stretching vibration of $\mathrm{TeO}_{4}$ is between 600 and $650 \mathrm{~cm}^{-1}$ [25].

The band around $640 \mathrm{~cm}^{-1}$ was assigned to $\mathrm{TeO}_{4}$ with bridging oxygen while the absorption band near $1230 \mathrm{~cm}^{-1}$ proved the presence of $\mathrm{BO}_{3}$. The presence of an observable shoulder at 993 and $996 \mathrm{~cm}^{-1}$ in 0.04 and 0.05 molar fraction of $\mathrm{La}_{2} \mathrm{O}_{3}$ NPs is due to the existence of $\mathrm{BO}_{4}$ units with bridging oxygen. The increment in steepness and the broadness of $\mathrm{BO}_{3}$ absorption band proposed that more boron oxide exist in $\mathrm{BO}_{3}$ structural configuration units with the addition of $\mathrm{La}_{2} \mathrm{O}_{3}$ NPs content. The absence of absorption band for $\mathrm{ZnO}$ and $\mathrm{La}_{2} \mathrm{O}_{3}$ in the FTIR spectra indicates that the zinc and lanthanum lattice are completely broken down [15].

3.4. Density and Molar Volume. Density $(\rho)$ of the fabricated glass samples is determined by applying Archimedes principle at room temperature through (1) while molar volume $\left(V_{m}\right)$ values are calculated and obtained by substituting obtained density values into (2).

$$
\begin{aligned}
\rho & =\frac{W_{\text {air }}}{V} \\
V_{m} & =\frac{\mathrm{MW}}{\rho},
\end{aligned}
$$

where $W_{\text {air }}$ is the weight of glass sample in air, $V$ is the volume of glass sample, and MW is the molecular weight of the glass sample.

The measured and calculated density and molar volume values are listed in Table 2 and depicted in Figure 4. $\mathrm{La}^{3+}$ ions with bigger atomic mass that replaced small atomic mass $\mathrm{B}^{3+}$ ions in the glass network are attributed to the increasing of density values of the samples [26].

According to the pioneering work of Wang et al. [29], when rare earth oxides are incorporated in the studied 
TABLE 1: Assignment of infrared transmission bands of $\left\{\left[\left(\mathrm{TeO}_{2}\right)_{0.7}\left(\mathrm{~B}_{2} \mathrm{O}_{3}\right)_{0.3}\right]_{0.7}(\mathrm{ZnO})_{0.3}\right\}_{1-x}\left(\mathrm{La}_{2} \mathrm{O}_{3} \mathrm{NPs}\right)_{x}$ with different molar fraction of $\mathrm{La}_{2} \mathrm{O}_{3}$ NPs.

\begin{tabular}{lcccccc}
\hline Number & 0.01 & 0.02 & 0.03 & 0.04 & 0.05 & Assignments \\
\hline 1 & 1230 & 1233 & 1235 & 1235 & 1236 & Asymmetric stretching relaxation of the B-O band of trigonal $\mathrm{BO}_{3}$ units [27]. \\
2 & - & - & - & 993 & 996 & $\mathrm{~B}-O_{\text {bond stretching of the tetrahedral } \mathrm{BO}_{4} \text { units [24]. }}$ \\
3 & 638 & 642 & 640 & 644 & 642 & $\mathrm{TeO}_{4}$ group exists in all tellurite containing glasses [25]. \\
4 & - & - & - & - & - & $\mathrm{ZnO}_{\text {participates in the glass network with } \mathrm{ZnO}_{4} \text { structural units and alternate TeO }}$ [15]. \\
5 & - & - & - & - & - & Vibration of La-O bond [28]. \\
\hline
\end{tabular}

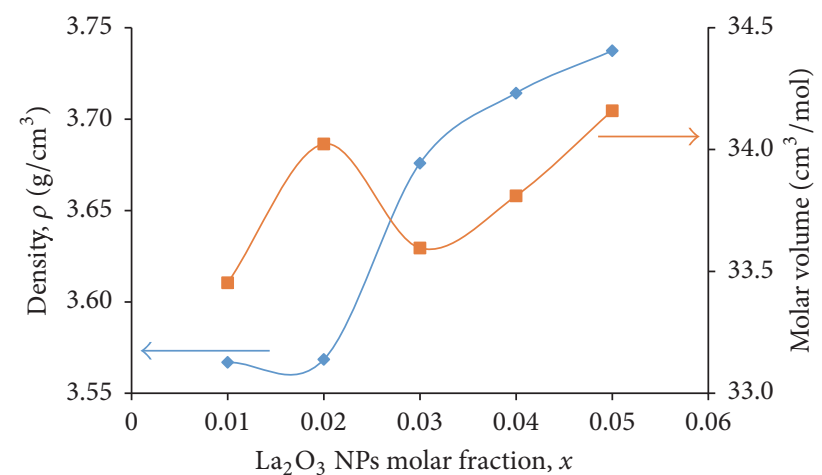

Figure 4: Density and molar volume of $\left\{\left[\left(\mathrm{TeO}_{2}\right)_{0.7}\left(\mathrm{~B}_{2} \mathrm{O}_{3}\right)_{0.3}\right]_{0.7}(\mathrm{ZnO})_{0.3}\right\}_{1-x}\left(\mathrm{La}_{2} \mathrm{O}_{3} \quad \mathrm{NPs}\right)_{x}$ with different molar fraction of $\mathrm{La}_{2} \mathrm{O}_{3}$ NPs.

TABLE 2: Density and molar volume of $\left\{\left[\left(\mathrm{TeO}_{2}\right)_{0.7}\left(\mathrm{~B}_{2} \mathrm{O}_{3}\right)_{0.3}\right]_{0.7}(\mathrm{ZnO})_{0.3}\right\}_{1-x} \quad\left(\mathrm{La}_{2} \mathrm{O}_{3} \quad \mathrm{NPs}\right)_{x}$ with different molar fraction of $\mathrm{La}_{2} \mathrm{O}_{3}$ NPs.

\begin{tabular}{lcc}
\hline $\mathrm{La}_{2} \mathrm{O}_{3}$ NPs molar fraction & Density $\left(\mathrm{g} / \mathrm{cm}^{3}\right)$ & $\begin{array}{c}\text { Molar volume } \\
\left(\mathrm{cm}^{3} / \mathrm{mol}\right)\end{array}$ \\
\hline 0.01 & 3.5669 & 33.4532 \\
0.02 & 3.5685 & 34.0228 \\
0.03 & 3.6759 & 33.5959 \\
0.04 & 3.7143 & 33.8101 \\
0.05 & 3.7374 & 34.1593 \\
\hline
\end{tabular}

glass, the molar volume of materials will show an increasing pattern. Increasing trend of molar volume as concentration of $\mathrm{La}_{2} \mathrm{O}_{3}$ NPs increases occurred due to the formation of $\mathrm{B}_{4}(\mathrm{La})$ units [29]. According to Doweidar and Saddeek [30], $\mathrm{La}_{2} \mathrm{O}_{3}$ contribute to the expansion of the glass network and thus increase the molar volume. Increment in molar volume indicates the increasing free space throughout the glass structure [24]. At 0.03 molar fraction of $\mathrm{La}_{2} \mathrm{O}_{3} \mathrm{NPs}$, the decrement of molar volume value is the result of inverse relationship between density and molar volume [31] and formation of nonbridging oxygen in the glass system.

3.5. Optical Absorption. The study of the optical absorption is able to grant important info about the optically induced transitions, band structure, and energy gap of a material [32]. For a crystalline material, the absorption edge will be very

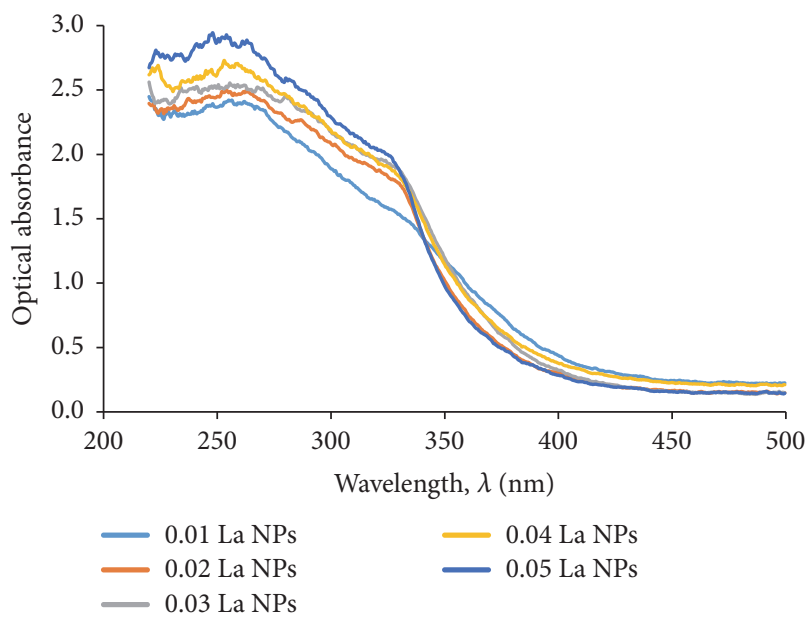

Figure 5: Optical absorbance of $\left\{\left[\left(\mathrm{TeO}_{2}\right)_{0.7}\left(\mathrm{~B}_{2} \mathrm{O}_{3}\right)_{0.3}\right]_{0.7}(\mathrm{ZnO})_{0.3}\right\}_{1-x} \quad\left(\mathrm{La}_{2} \mathrm{O}_{3} \mathrm{NPs}\right)_{x}$ with different molar fraction of $\mathrm{La}_{2} \mathrm{O}_{3} \mathrm{NPs}$.

sharp whereas in an amorphous material the fundamental absorption edge will has a finite slope [33].

Figure 5 illustrates the optical absorption spectra of the glass samples in the ultraviolet region. As seen in Figure 5, the absence of sharp absorption edge validates the glassy state of the prepared samples. Meanwhile, the shifting of the fundamental absorption edge towards shorter wavelength occurs because of the increasing field strength of the $\mathrm{La}^{3+}$ ion as $\mathrm{La}_{2} \mathrm{O}_{3}$ NPs concentration increases in the glass system [34].

3.6. Optical Band Gap. In amorphous material, optical transitions that take place at the fundamental absorption edge are separated into two types, that is, direct transitions where the momentum of the electron is conserved and indirect transitions in which the cooperation from a phonon is necessary [35]. The optical band gap values are calculated via Mott and Davis relation that connects the absorption coefficient with incident photon energy [36]:

$$
\alpha \hbar \omega=B\left(\hbar \omega-E_{\mathrm{opt}}\right)^{n},
$$

where $B$ is a constant which is energy-independent and is known as the band-tailing parameter and $\hbar \omega$ represent the incident photon energy while constant $n$ depends on the type of transition ( $n=2$ for indirect transition and $n=1 / 2$ for direct transition). 


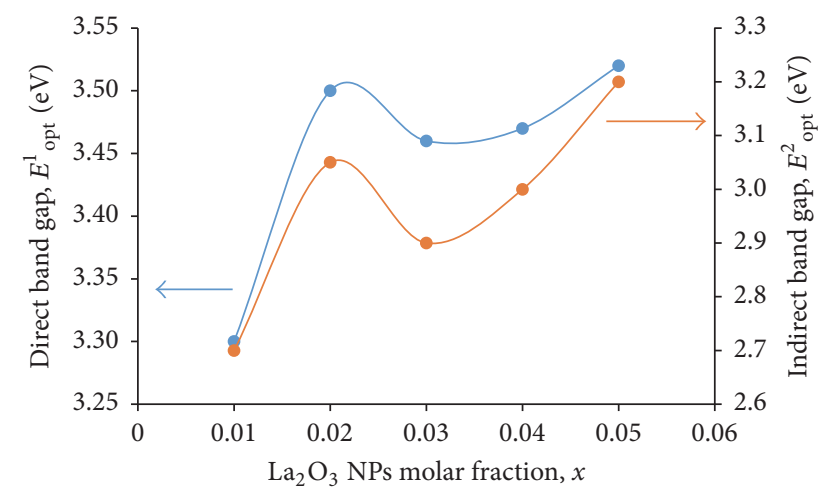

FIGURE 6: Direct and indirect energy band gap of $\left\{\left[\left(\mathrm{TeO}_{2}\right)_{0.7}\left(\mathrm{~B}_{2} \mathrm{O}_{3}\right)_{0.3}\right]_{0.7}(\mathrm{ZnO})_{0.3}\right\}_{1-x}\left(\mathrm{La}_{2} \mathrm{O}_{3} \mathrm{NPs}\right)_{x}$ with different molar fraction of La NPs.

TABLE 3: Direct and indirect energy band gap of $\left\{\left[\left(\mathrm{TeO}_{2}\right)_{0.7}\left(\mathrm{~B}_{2} \mathrm{O}_{3}\right)_{0.3}\right]_{0.7}(\mathrm{ZnO})_{0.3}\right\}_{1-x}\left(\mathrm{La}_{2} \mathrm{O}_{3} \mathrm{NPs}\right)_{x}$ with different molar fraction of La NPs.

\begin{tabular}{lcc}
\hline $\begin{array}{l}\mathrm{La}_{2} \mathrm{O}_{3} \text { NPs molar } \\
\text { fraction }\end{array}$ & $\begin{array}{c}\text { Direct band gap, } \\
E_{\text {opt }}^{1}(\mathrm{eV})\end{array}$ & $\begin{array}{c}\text { Indirect band gap, } \\
E_{\text {opt }}^{2}(\mathrm{eV})\end{array}$ \\
\hline 0.01 & 3.30 & 2.70 \\
0.02 & 3.50 & 3.05 \\
0.03 & 3.46 & 2.90 \\
0.04 & 3.47 & 3.00 \\
0.05 & 3.52 & 3.20 \\
\hline
\end{tabular}

Equation (3) is readjusted to represent direct energy band gap equation in (4) and indirect energy band gap equation in (5).

$$
\begin{aligned}
(\alpha \hbar \omega)^{2} & =B\left(\hbar \omega-E_{\mathrm{opt}}\right) \\
(\alpha \hbar \omega)^{1 / 2} & =B\left(\hbar \omega-E_{\mathrm{opt}}\right) .
\end{aligned}
$$

The computed direct and indirect energy band gap values are shown in Table 3 and plotted in Figure 6. Graphs were plotted based on (4) and (5) in order to see whether optical data on the sample glasses fit better to direct or indirect band gap formula. It is already well known that amorphous materials have a reasonable fit to equation for indirect band gap [37]. The presence of bridging oxygen in the glassy network is attributed to the increment of $E_{g}$ values [38]. Hence, the incorporation of $\mathrm{La}_{2} \mathrm{O}_{3}$ NPs into the glass network has made it harder for the electrons to move within the fabricated materials [39]. The drastic decrement of energy band gap value may result from a significant structural change that occurred in the glass system at glass sample with 0.03 molar fraction of $\mathrm{La}_{2} \mathrm{O}_{3}$ NPs [40].

3.7. Urbach Energy. In an amorphous material, short range of periodic lattice arrangement is linked to the tailing of the density of states into the forbidden energy band [41]. The width of band tails, also known as Urbach energy $(\Delta E)$, originated from electron transition between localized states [42]. Urbach energy is a measure of defects concentration and

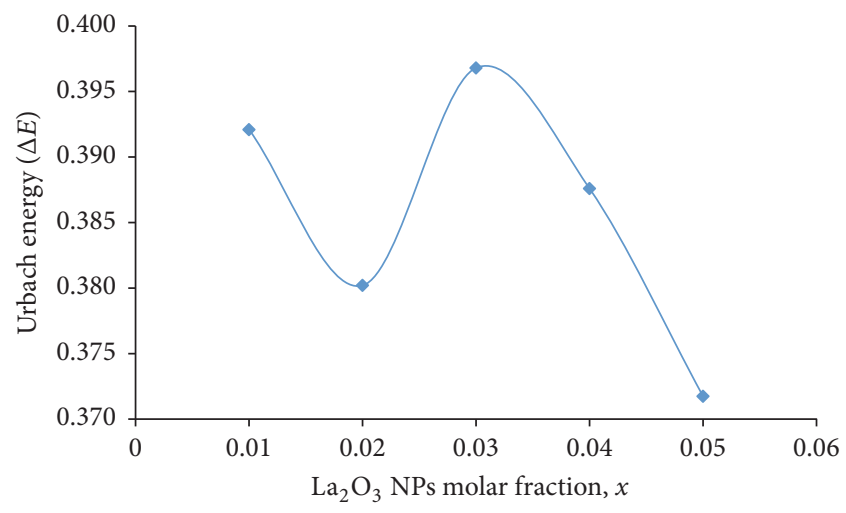

FIGURE 7: Urbach energy of $\left\{\left[\left(\mathrm{TeO}_{2}\right)_{0.7}\left(\mathrm{~B}_{2} \mathrm{O}_{3}\right)_{0.3}\right]_{0.7}(\mathrm{ZnO})_{0.3}\right\}_{1-x}$ $\left(\mathrm{La}_{2} \mathrm{O}_{3} \mathrm{NPs}\right)_{x}$ with different molar fraction of La NPs.

the degree of disorder in amorphous solids where materials with higher value of $\Delta E$ will have higher chances to transform weak bonds into defects [33]. $\Delta E$ are expressed by the following equation:

$$
\alpha(\omega)=B \exp \left(\frac{\hbar \omega}{\Delta E}\right)
$$

where $B$ is a constant, $\hbar \omega$ is photon energy, and $\alpha(\omega)$ is the absorption coefficient.

Urbach energy $(\Delta E)$ values are determined from the slopes of linear regions of the plots $\ln \alpha$ versus $\hbar \omega$ [43]. Calculated and acquired $\Delta E$ values are revealed in Figure 7. From Figure 7, decreasing trend of $\Delta E$ can be observed as content of $\mathrm{La}_{2} \mathrm{O}_{3}$ NPs in the glass system increases. The decreasing pattern of $\Delta E$ is associated with decreasing number of defects in the glass matrix [44]. Defects that occur within the glass network, for instance, increasing number of nonbridging oxygen and cation-anion vacancy pair, might be the reason behind the increment of $\Delta E$ value at 0.03 molar fraction of $\mathrm{La}_{2} \mathrm{O}_{3}$ NPs [45].

3.8. Refractive Index. The propagation of electromagnetic wave was influenced by optical constant of the materials like refractive index $(n)$, extinction coefficient, and others [46]. The relationship between $n$ and $E_{\text {opt }}$ was established by the following equation [47]:

$$
\frac{\left(n^{2}-1\right)}{\left(n^{2}+2\right)}=1-\sqrt{\frac{E_{\mathrm{opt}}}{20}},
$$

where $E_{\text {opt }}$ represent the indirect band gap values.

Figure 8 demonstrates the plot of refractive index values versus the variation in molar fraction of $\mathrm{La}_{2} \mathrm{O}_{3}$ NPs while the exact values of refractive index are given in Table 4 . Refractive index can be correlated and clarified through the formation of bridging and nonbridging oxygen in a material.

In this research, as amount of $\mathrm{La}_{2} \mathrm{O}_{3}$ NPs increases, the presence of low polarizability bridging oxygen in the glass network had led to the decreasing trend of refractive index. Meanwhile, structural change that occurs in 0.03 


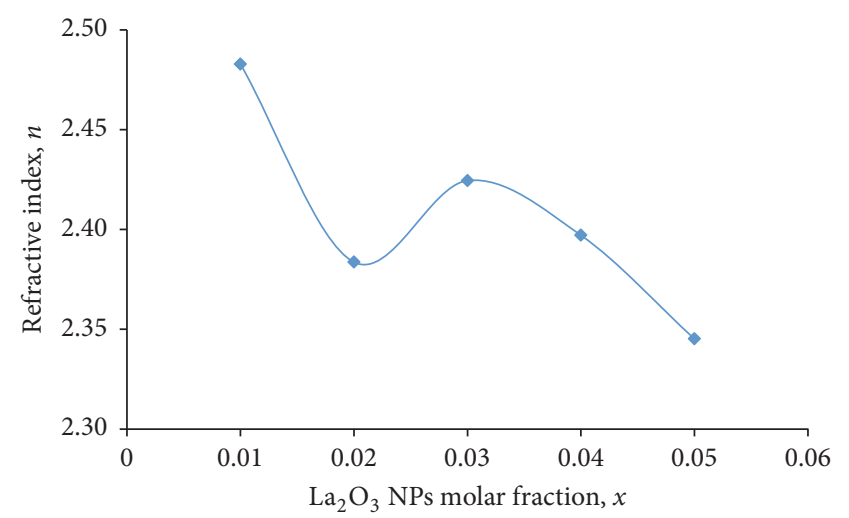

FIgURE 8: Refractive index and polarizability of $\left\{\left[\left(\mathrm{TeO}_{2}\right)_{0.7}\left(\mathrm{~B}_{2} \mathrm{O}_{3}\right)_{0.3}\right]_{0.7}(\mathrm{ZnO})_{0.3}\right\}_{1-x}\left(\mathrm{La}_{2} \mathrm{O}_{3} \quad \mathrm{NPs}\right)_{x}$ with different molar fraction of La NP.

TABLE 4: Refractive index and polarizability of $\left\{\left[\left(\mathrm{TeO}_{2}\right)_{0.7}\left(\mathrm{~B}_{2} \mathrm{O}_{3}\right)_{0.3}\right]_{0.7}(\mathrm{ZnO})_{0.3}\right\}_{1-x} \quad\left(\mathrm{La}_{2} \mathrm{O}_{3} \quad \mathrm{NPs}\right)_{x}$ with different molar fraction of La NPs.

\begin{tabular}{lc}
\hline $\mathrm{La}_{2} \mathrm{O}_{3}$ NPs molar fraction & Refractive index \\
\hline 0.01 & 2.4829 \\
0.02 & 2.3837 \\
0.03 & 2.4245 \\
0.04 & 2.3971 \\
0.05 & 2.3452 \\
\hline
\end{tabular}

molar fraction of $\mathrm{La}_{2} \mathrm{O}_{3}$ NPs resulted in drastic formation of nonbridging oxygen. Since nonbridging oxygen generates more ionic bonds and they manifest themselves in a larger polarizability over the mostly covalent bonds of bridging oxygen, thus a higher value of refractive index value is recorded when the amount of nonbridging oxygen is more than bridging oxygen in the material [48]. From the result, zinc borotellurite glass doped with lanthanum nanoparticles has higher refractive index values when compared to the pure silicate glass which is widely used as fiber material in the industry.

\section{Conclusion}

Zinc borotellurite glasses doped with lanthanum oxide nanoparticles have been successfully fabricated. The structural, physical, and optical properties of the prepared samples were investigated and reported in detail. The presence of lanthanum oxide nanoparticles in the glass matrix was verified through TEM. The amorphous nature of the samples was proven by the presence of broad hump in XRD diffraction pattern. Optical energy band gap values increases with refractive index decrease are due to the increasing amount of low polarizable bridging oxygen with the increment of $\mathrm{La}_{2} \mathrm{O}_{3}$ NPs content. The decreasing pattern for Urbach energy value indicates that the fabricated glasses were becoming less fragile. Variation of pattern in 0.03 molar fraction of $\mathrm{La}_{2} \mathrm{O}_{3}$ NPs for molar volume, energy band gap, Urbach energy, and refractive index is due to structural change in the glass system that leads to more creation of nonbridging oxygen and can be further confirmed through FTIR spectroscopy. The most essential optical parameter, the refractive index, values of the prepared glass obtained are higher than the pure tellurite glass and the common fiber material, pure silicate glass. This suggests that zinc borotellurite glass doped with lanthanum nanoparticles is a promising material for fabricating optical fiber as well as application in the optoelectronic and photonic field. Optical parameters for zinc borotellurite glasses doped with $\mathrm{La}_{2} \mathrm{O}_{3}$ NPs attained from this research would be important and come in handy in the process of designing rare earth containing optical functional glasses and optoelectronic devices in the future.

\section{Conflicts of Interest}

The authors declare that there are no conflicts of interest regarding the publication of this paper.

\section{Acknowledgments}

This work was supported by the Ministry of Higher Education of Malaysia and University Putra Malaysia through GPIBT [Grant no. 9411800].

\section{References}

[1] F. Angeli, T. Charpentier, E. Molières, A. Soleilhavoup, P. Jollivet, and S. Gin, "Influence of lanthanum on borosilicate glass structure: a multinuclear MAS and MQMAS NMR investigation," Journal of Non-Crystalline Solids, vol. 376, pp. 189-198, 2013.

[2] B. V. R. Chowdari and P. P. Kumari, "Studies on $\mathrm{Ag}_{2} \mathrm{O} \cdot \mathrm{M}_{x} \mathrm{O}_{y} \cdot \mathrm{TeO}_{2}\left(\mathrm{M}_{x} \mathrm{O}_{y}=\mathrm{WO}_{3}, \mathrm{MoO}_{3}, \mathrm{P}_{2} \mathrm{O}_{5}\right.$ and $\left.\mathrm{B}_{2} \mathrm{O}_{3}\right)$ ionic conducting glasses," Solid State Ionics, vol. 113, pp. 665-675, 1998.

[3] M. N. Azlan, M. K. Halimah, S. Z. Shafinas, and W. M. Daud, "Electronic polarizability of zinc borotellurite glass system containing erbium nanoparticles," Materials Express, vol. 5, no. 3, pp. 211-218, 2015.

[4] I. Jlassi, H. Elhouichet, and M. Ferid, "Thermal and optical properties of tellurite glasses doped erbium," Journal of Materials Science, vol. 46, no. 3, pp. 806-812, 2011.

[5] S. S. Babu, K. Jang, E. H. Cho, H. Lee, and C. K. Jayasankar, "Thermal, structural and optical properties of $\mathrm{Eu}^{3+}$-doped zinctellurite glasses," Journal of Physics D: Applied Physics, vol. 40, no. 18, pp. 5767-5774, 2007.

[6] L. D. Pye, V. D. Fréchette, and N. J. Kreidl, Borate Glasses: Structure, Properties, Applications, vol. 12, Springer Science \& Business Media, New York, NY, USA, 2012.

[7] Z. A. S. Mahraz, M. R. Sahar, and S. K. Ghoshal, "Band gap and polarizability of boro-tellurite glass: influence of erbium ions," Journal of Molecular Structure, vol. 1072, no. 1, pp. 238-241, 2014.

[8] P. G. Pavani, K. Sadhana, and V. C. Mouli, "Optical, physical and structural studies of boro-zinc tellurite glasses," Physica B: Condensed Matter, vol. 406, no. 6-7, pp. 1242-1247, 2011.

[9] A. Neumann and D. Walter, "The thermal transformation from lanthanum hydroxide to lanthanum hydroxide oxide," Thermochimica Acta, vol. 445, no. 2, pp. 200-204, 2006. 
[10] P. Nandi, A. Srinivasan, and G. Jose, "Structural dependent thermal and optical properties of rare earth doped glass with mixed glass formers," Optical Materials, vol. 31, no. 4, pp. 653659, 2009.

[11] R. Vajtai, Ed., Springer Handbook of Nanomaterials, Springer Science \& Business Media, 2013.

[12] M. K. Halimah, M. N. Azlan, and S. Z. Shafinas, "Optical properties of erbium doped borotellurite glass system," Advanced Materials Research, vol. 1112, pp. 7-10, 2015.

[13] M. N. Azlan, M. K. Halimah, S. Z. Shafinas, W. M. Daud, and H. A. A. Sidek, "Influence of erbium concentration on spectroscopic properties of tellurite based glass," Solid State Science and Technology, vol. 22, no. 1-2, pp. 148-156, 2014.

[14] A. M. Noorazlan, H. M. Kamari, S. S. Zulkefly, and D. W. Mohamad, "Effect of erbium nanoparticles on optical properties of zinc borotellurite glass system," Journal of Nanomaterials, vol. 2013, Article ID 940917, 8 pages, 2013.

[15] S. S. Hajer, M. K. Halimah, Z. Azmi, and M. N. Azlan, "Optical properties of zinc-borotellurite doped samarium," Chalcogenide Letters, vol. 11, no. 11, pp. 553-566, 2014.

[16] S. S. Hajer, M. K. Halimah, A. Zakaria, and M. N. Azlan, "Effect of samarium nanoparticles on optical properties of zinc borotellurite glass system," in Materials Science Forum, vol. 846, pp. 63-68, Trans Tech Publications, 2016.

[17] A. M. Noorazlan, H. M. Kamari, S. O. Baki, and D. W. Mohamad, "Green emission of tellurite based glass containing erbium oxide nanoparticles," Journal of Nanomaterials, vol. 2015, Article ID 952308, 9 pages, 2015.

[18] J. C. Sabadel, P. Armand, D. Cachau-Herreillat et al., "Structural and nonlinear optical characterizations of tellurium oxidebased glasses: $\mathrm{TeO}_{2}-\mathrm{BaO}-\mathrm{TiO}_{2}$," Journal of Solid State Chemistry, vol. 132, no. 2, pp. 411-419, 1997.

[19] W. Vogel, Glass Chemistry, Springer, Berlin, Germany, 1994.

[20] G. Cao and Y. Wang, Nanostructures and Nanomaterials: Synthesis, Properties, and Applications, World Scientific, Singapore, 2011.

[21] H. T. Smyth, "The structure of glass," in Introduction to Glass Science, L. D. Pye, H. J. Stevens, and W. C. LaCourse, Eds., pp. 61-100, Springer US, New York, NY, USA, 1972.

[22] J. R. Ferraro, M. H. Manghnan, and A. Quattroc, "Infraredspectra of several glasses at high-pressures," Physics and Chemistry of Glasses, vol. 13, no. 4, p. 116, 1972.

[23] S. R. Elliott, Physics of Amorphous Materials, vol. 13, Longman, London, UK, 1983.

[24] P. Vasantharani and N. Sangeetha, "Characterization of lead based binary and ternary glass systems using spectroscopic methods," International Journal of Research in Pure and Applied Physics, vol. 3, no. 1, pp. 1-6, 2013.

[25] M. F. Faznny, M. K. Halimah, and M. N. Azlan, "Effect of lanthanum oxide on optical properties of zinc borotellurite glass system," Journal of Optoelectronics and Biomedical Materials, vol. 8, no. 2, pp. 49-59, 2016.

[26] C. Rajyasree, P. M. V. Teja, K. V. R. Murthy, and D. K. Rao, "Optical and other spectroscopic studies of lead, zinc bismuth borate glasses doped with CuO," Physica B: Condensed Matter, vol. 406, no. 23, pp. 4366-4372, 2011.

[27] S. G. Motke, S. P. Yawale, and S. S. Yawale, "Infrared spectra of zinc doped lead borate glasses," Bulletin of Materials Science, vol. 25, no. 1, pp. 75-78, 2002.

[28] L.-G. Hwa, Y.-R. Chang, and S.-P. Szu, "Optical and physical properties of lanthanum gallogermanate glasses," Journal of Non-Crystalline Solids, vol. 231, no. 3, pp. 222-226, 1998.
[29] M.-T. Wang, J.-S. Cheng, M. Li, and F. He, "Structure and properties of soda lime silicate glass doped with rare earth," Physica B: Condensed Matter, vol. 406, no. 2, pp. 187-191, 2011.

[30] H. Doweidar and Y. B. Saddeek, "Effect of $\mathrm{La}_{2} \mathrm{O}_{3}$ on the structure of lead borate glasses," Journal of Non-Crystalline Solids, vol. 356, no. 28-30, pp. 1452-1457, 2010.

[31] M. H. Shaaban and A. A. Ali, "Density, electrical and optical properties of yttrium-containing tellurium bismuth borate glasses," Journal of Electronic Materials, vol. 43, no. 11, pp. 40234032, 2014.

[32] A. A. Higazy and A. Hussein, "Optical absorption studies of $\gamma$ irradiated magnesium phosphate glasses," Radiation Effects and Defects in Solids, vol. 133, no. 3, pp. 225-235, 1995.

[33] S. El-Rabaie, T. A. Taha, and A. A. Higazy, "Non-linear optical and electrical properties of germanate glasses," Physica B: Condensed Matter, vol. 429, pp. 1-5, 2013.

[34] K. Terashima, S. Tamura, S.-H. Kim, and T. Yoko, "Structure and nonlinear optical properties of lanthanide borate glasses," Journal of the American Ceramic Society, vol. 80, no. 11, pp. 2903-2909, 1997.

[35] C. A. Hogarth and E. Assadzadeh-Kashani, "Some studies of the optical properties of tungsten-calcium-tellurite glasses," Journal of Materials Science, vol. 18, no. 4, pp. 1255-1263, 1983.

[36] C. Mrabet, A. Boukhachem, M. Amlouk, and T. Manoubi, "Improvement of the optoelectronic properties of tin oxide transparent conductive thin films through lanthanum doping," Journal of Alloys and Compounds, vol. 666, pp. 392-405, 2016.

[37] M. Abdel-Baki and F. El-Diasty, "Optical properties of oxide glasses containing transition metals: case of titanium- and chromium-containing glasses," Current Opinion in Solid State and Materials Science, vol. 10, no. 5-6, pp. 217-229, 2006.

[38] M. S. Malik and C. A. Hogarth, "Some optical properties of $\mathrm{TeO}_{2}-\mathrm{CuO}-\mathrm{Lu}_{2} \mathrm{O}_{3}$ glasses," Journal of Materials Science Letters, vol. 8, no. 6, pp. 655-659, 1989.

[39] Z. A. Talib, W. M. Daud, E. Z. M. Tarmizi, H. A. A. Sidek, and W. M. M. Yunus, "Optical absorption spectrum of $\mathrm{Cu}_{2} \mathrm{O}-\mathrm{CaO}-$ $\mathrm{P}_{2} \mathrm{O}_{5}$ glasses," Journal of Physics and Chemistry of Solids, vol. 69, no. 8, pp. 1969-1973, 2008.

[40] P. Nagels, L. Tichý, A. Tríska, and H. Ticha, "Physical properties of $\left(\mathrm{GeS}_{2}\right)_{x}\left(\mathrm{Bi}_{2} \mathrm{~S}_{3}\right)_{1-x}$ glasses," Journal of Non-Crystalline Solids, vol. 77, pp. 1265-1268, 1985.

[41] L. M. S. El-Deen, M. S. A. Salhi, and M. M. Elkholy, "IR and UV spectral studies for rare earths-doped tellurite glasses," Journal of Alloys and Compounds, vol. 465, no. 1-2, pp. 333-339, 2008.

[42] P. Tarte, "The determination of cation co-ordination in glasses by infra-red spectroscopy," in Physics of Non-Crystalline Solids, p. 549, Elsevier, Amsterdam, The Netherlands, 1964.

[43] S. L. S. Rao, G. Ramadevudu, M. Shareefuddin, A. Hameed, M. N. Chary, and M. L. Rao, "Optical properties of alkaline earth borate glasses," International Journal of Engineering, Science and Technology, vol. 4, no. 4, pp. 25-35, 2013.

[44] S. Y. Marzouk and M. A. Azooz, "Optical properties of $\mathrm{CeO}_{2}$ doped $\mathrm{SiO}_{2}-\mathrm{Na}_{2} \mathrm{O}-\mathrm{CaO}-\mathrm{P}_{2} \mathrm{O}_{5}$ glasses," Silicon, vol. 4, no. 3, pp. 157-165, 2012.

[45] A. Azuraida, M. K. Halimah, C. A. C. Azurahanim, and M. Ishak, "Gamma irradiation effect on structural and optical properties of bismuth-boro-tellurite glasses," Advanced Materials Research, vol. 1107, pp. 426-431, 2015.

[46] R. S. Gedam and D. D. Ramteke, "Electrical and optical properties of lithium borate glasses doped with $\mathrm{Nd}_{2} \mathrm{O}_{3}$," Journal of Rare Earths, vol. 30, no. 8, pp. 785-789, 2012. 
[47] R. El-Mallawany, M. D. Abdalla, and I. A. Ahmed, "New tellurite glass: optical properties," Materials Chemistry and Physics, vol. 109, no. 2-3, pp. 291-296, 2008.

[48] Y. B. Saddeek, K. A. Aly, A. Dahshan, and I. M. E. Kashef, "Optical properties of the $\mathrm{Na}_{2} \mathrm{O}-\mathrm{B}_{2} \mathrm{O}_{3}-\mathrm{Bi}_{2} \mathrm{O}_{3}-\mathrm{MoO}_{3}$ glasses," Journal of Alloys and Compounds, vol. 494, no. 1-2, pp. 210-213, 2010. 

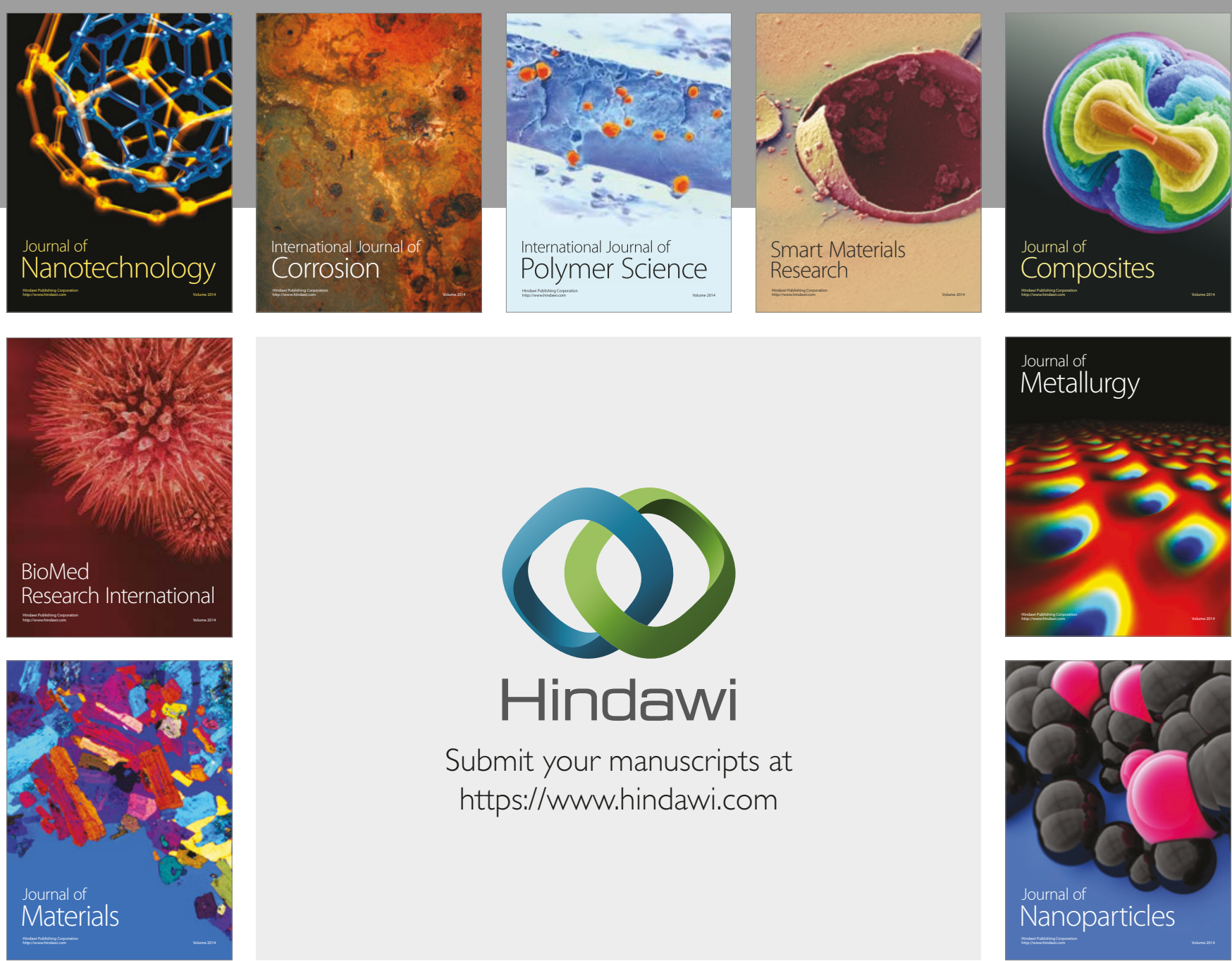

\section{Hindawi}

Submit your manuscripts at

https://www.hindawi.com
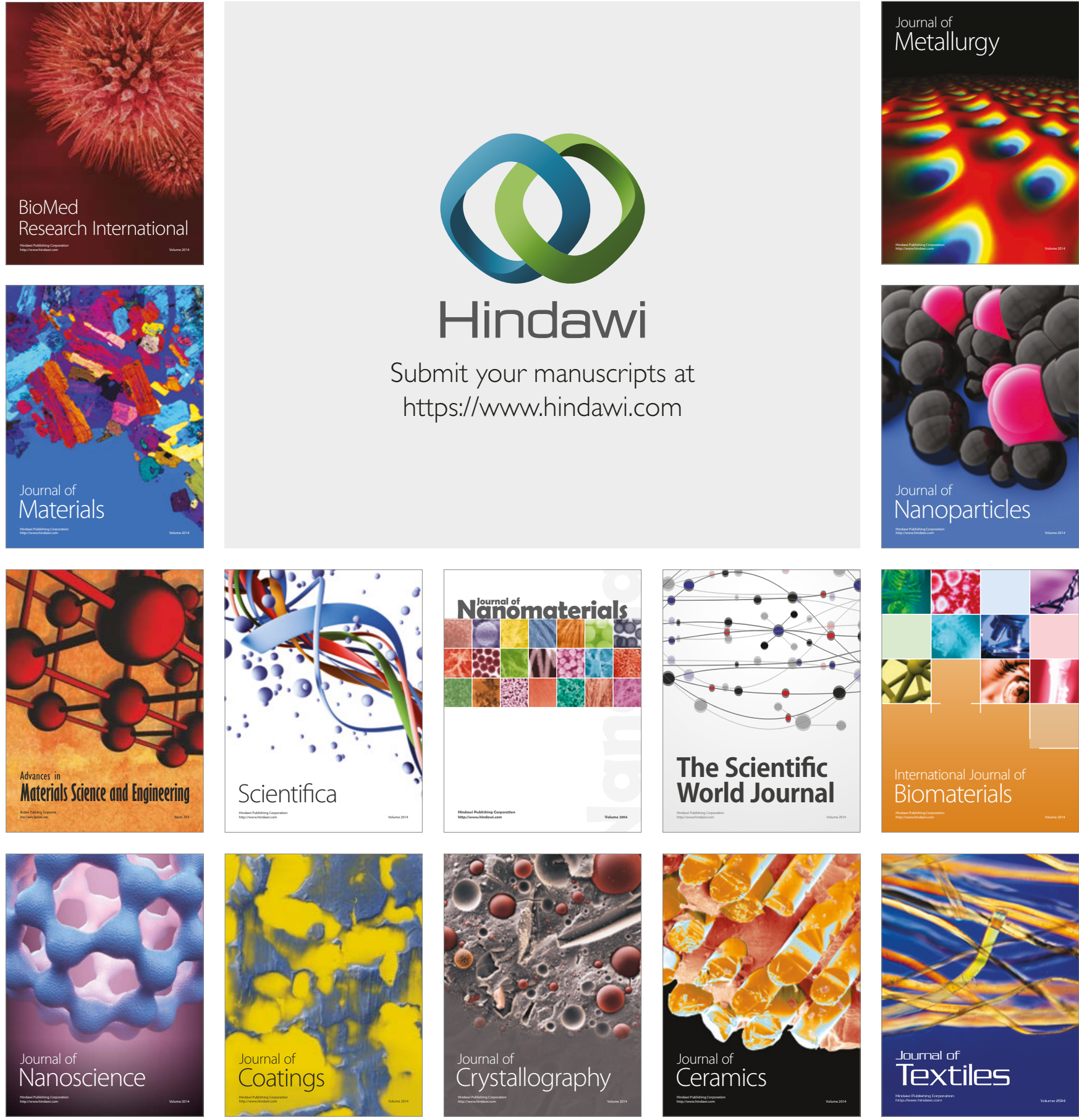

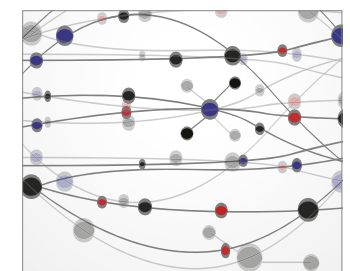

The Scientific World Journal
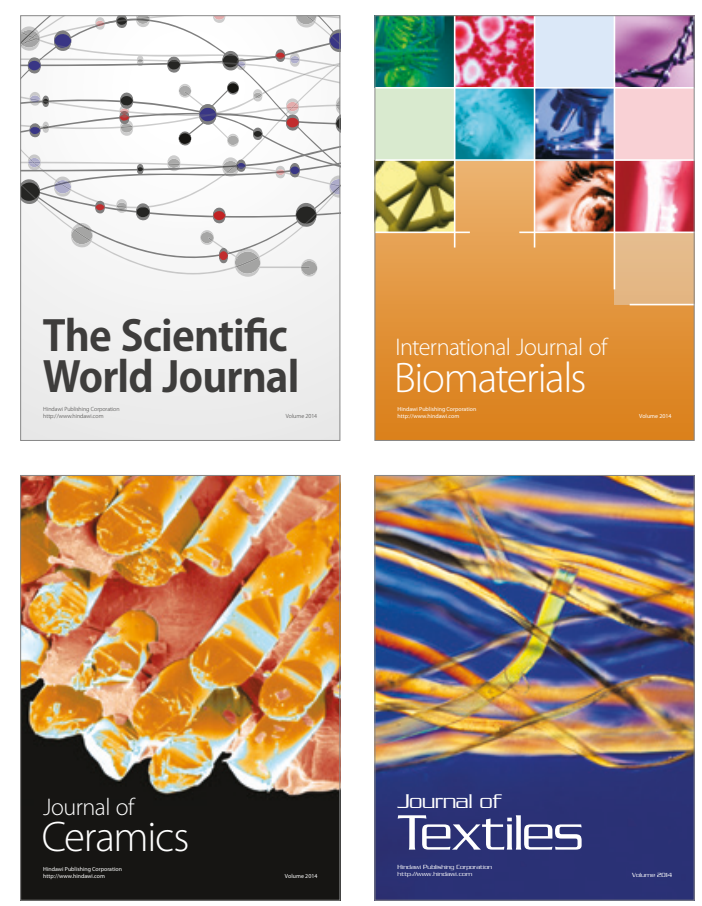